\title{
A cylindrical furnace for absorption spectral studies
}

\author{
R VENKATASUBRAMANIAN
}

Spectroscopy Division, Bhabha Atomic Research Centre, Mumbai 400 085, India

e-mail: rvs1@vsnl.com; bjshetty@apsara.barc.ernet.in

MS received 25 October 2000; revised 4 April 2001

\begin{abstract}
A cylindrical furnace with three heating zones, capable of providing a temperature of $1100^{\circ} \mathrm{C}$, has been fabricated to enable recording of absorption spectra of high temperature species. The temperature of the furnace can be controlled to $\pm 1^{\circ} \mathrm{C}$ of the set temperature. The salient feature of this furnace is that the material being heated can be prevented from depositing on the windows of the absorption cell by maintaining a higher temperature at both the ends of the absorption cell.
\end{abstract}

Keywords. Electrical furnace; free radicals; absorption spectra; high temperature species.

\section{Introduction}

In order that high temperature species such as atoms, radicals and molecules can be studied through their absorption spectra, a cylindrical furnace has been fabricated in our laboratory. The components and accessories required for operating this furnace are described here. The salient feature of this furnace is that it contains three separate heating zones. The heating zone at either end provides a higher temperature compared to the one at the centre. As a result, it has the following advantage. Depositing of the material being heated on the window of the absorption cell can be avoided and thus the transmitted light from the continuum light source after passing through the absorbing species can reach the spectrograph or the detector without any obstruction. A brief description of this furnace is presented in this paper.

\section{Construction of the furnace}

A silica tube of $90 \mathrm{~cm}$ length and $7 \mathrm{~cm}$ diameter was employed and nichrome wire was wound over it at both ends as well as at the centre. Three heating zones were thus created. The silica tube was thermally well-insulated by closely packing it with alumina wool. This was surrounded by an aluminium casing having the required holes for the 


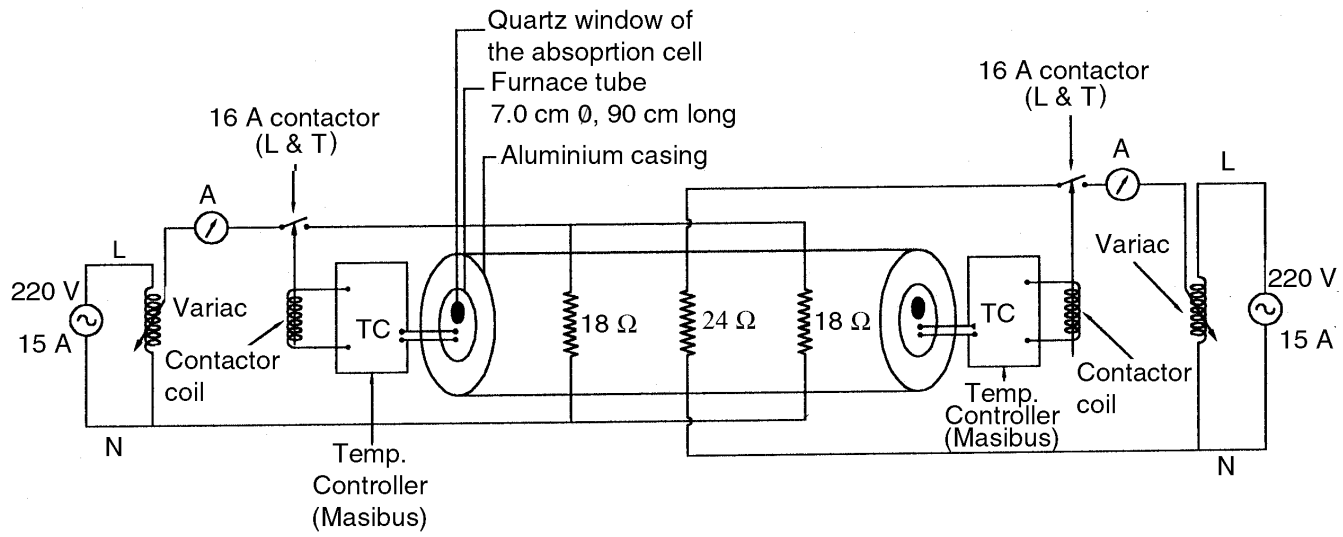

Figure 1. Circuit diagram of cylindrical furnace.

electrical terminals and the necessary provision at either end for the continuum light to pass through.

The end windings were connected in parallel to a 15 -ampere dimmerstat through an ammeter. A Masibus temperature controller, a relay switch and a chromel-alumel thermocouple were added in the circuit as shown in figure 1 . The technical details of the furnace components are provided in table 1. A photograph of the furnace thus constructed is shown in figure 2 .

Table 1. Technical details of the furnace components.

\begin{tabular}{lll}
\hline Max. temperature obtained & $:$ & $1100^{\circ} \mathrm{C}$ \\
Temp. control & $:$ & $\pm 1{ }^{\circ} \mathrm{C}$ of the Set Temp. \\
Furnace tube & $:$ & Silica tube $90 \mathrm{~cm}$ long, $7 \mathrm{~cm}$ dia \\
Winding material & $:$ & Nichrome wire \\
Heating zone & $:$ & Chos. \\
Thermocouple & $:$ & Masibus $(2$ nos.) \\
Temp. controller & $:$ & 15 amp $(2$ nos.) \\
Variac & $:$ & Alumina wool \\
Insulating material & $:$ & Ammeter, relay switch (2 nos each) \\
Accessories & $:$ & 18 ohms \\
Resistance of the end windings & 24 ohms \\
Resistance of central winding & $:$ & L \& T make (16 amps) \\
Relay switch/contactor & $:$ &
\end{tabular}

Salient feature. Extreme zones are kept at higher temperatures, $20-30^{\circ} \mathrm{C}$ more than the central zone so that the deposition of the material being heated on the quartz window of the absorption cell can be avoided. 


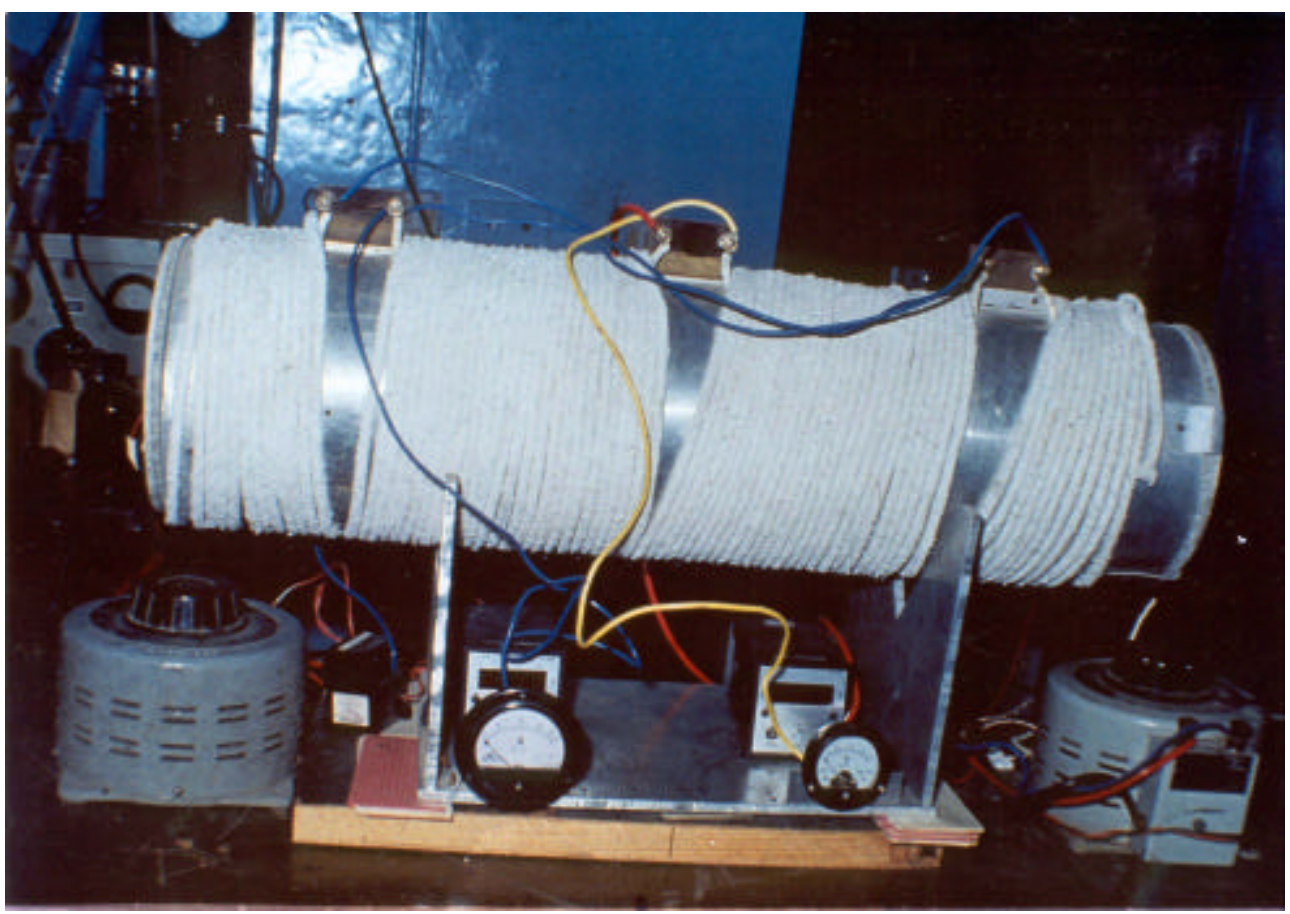

Figure 2. Photograph of cylindrical furnace for absorption spectral studies.

\section{Performance evaluation of the furnace}

In order to evaluate the performance of the cylindrical furnace thus constructed for absorption spectral studies, the following experiment was carried out. A quartz absorption cell, of $70 \mathrm{~cm}$ length and $2.5 \mathrm{~cm}$ diameter, with two sealed-in windows containing a few drops of mercury was prepared and kept inside the furnace after evacuation and sealed following the addition of a few torr of rare gas. The window of the absorption cell kept inside the furnace was made to face the slit of a Hilger medium quartz prism spectrograph. Light from a xenon continuum lamp was made to pass through the absorption cell. The furnace was switched on. As a result of heating, $\mathrm{Hg}_{2}$

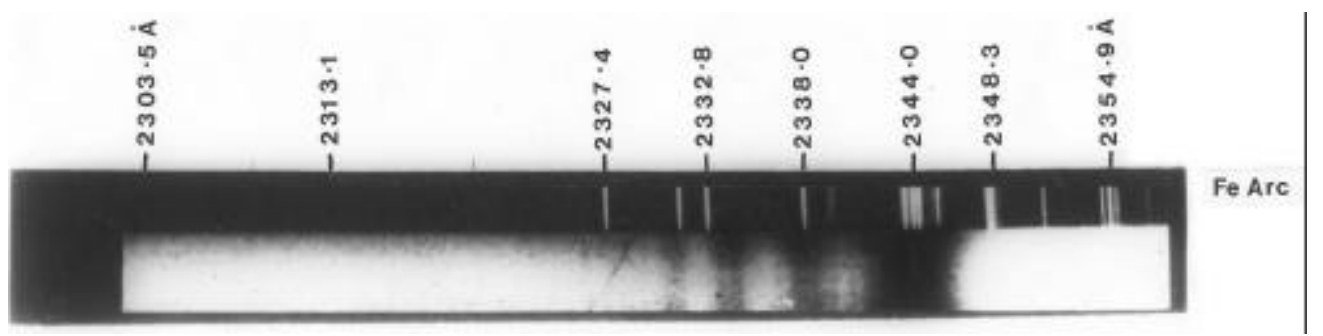

Figure 3. Absorption spectrum of $I \leftarrow X$ band system of $\mathrm{Hg}_{2}$ molecule at $\sim 2345 \AA$. 
molecule was formed in the absorption cell and its absorption spectrum was recorded at five different temperatures ranging from $150^{\circ} \mathrm{C}$ to $1100^{\circ} \mathrm{C}$. The spectrum recorded at $300^{\circ} \mathrm{C}$ contained a strong continuum commencing at about $2345 \AA$ and fading out to shorter wavelengths with superposed diffuse bands. The maxima of these diffuse bands were observed at $2342,2337,2333$ and $2330 \AA$ as can be seen in figure 3 . These bands correspond to the bound-free transition $\left[I^{3} \Pi_{u} \leftrightarrow X^{1} \Sigma_{g}{ }^{+}\right]$of the $\mathrm{Hg}_{2}$ molecule (Lord Rayleigh 1927; Mies et al 1978). The absorption spectrum of $\mathrm{Hg}_{2}$ molecule was studied because of the interest in mercury excimer laser research. Mercury and the few torr of rare gas contained in the absorption cell were heated at the following temperatures provided by the furnace. The spectra recorded at each of these temperatures are listed below.

Temperature of the furnace

$150^{\circ} \mathrm{C}$

$300^{\circ} \mathrm{C}$

$500^{\circ} \mathrm{C}$

$900^{\circ} \mathrm{C}$

$1100^{\circ} \mathrm{C}$
Absorption spectrum obtained

$2540 \AA$ band of $\mathrm{Hg}_{2}$ and $2536 \AA$ line of $\mathrm{Hg}$ $2345 \AA$ band of $\mathrm{Hg}_{2}$

$2540 \AA$ band broadens and extends to higher wavelengths. A large number of absorption bands start appearing between $2600 \AA$ and $2900 \AA$ Complete absorption below $3000 \AA$. In addition, four sharp lines at 3230, 3256, 3263 and $3358 \AA$ are observed. Some of these lines have been identified as due to the atomic spectrum of cadmium present as an impurity in mercury

In addition to the above features recorded at $900^{\circ} \mathrm{C}$, the line at $3230 \AA$ is found to have a shading towards red.

In addition to the above test, the furnace was employed for the synthesis of indium monobromide $(\mathrm{InBr})$ by heating a small quantity of metallic indium in the presence of bromine $\left(\mathrm{Br}_{2}\right)$ and neon in a quartz absorption cell. By heating the freshly synthesized $\mathrm{InBr}$ compound at $250^{\circ} \mathrm{C}$, it was possible to record on the Hilger medium quartz spectrograph, the electronic absorption spectrum of $C^{1} \Pi \leftarrow X^{1} \Sigma$ system of $\mathrm{InBr}$ at $\sim 2800 \AA$. The bands of $C \leftarrow X$ system of $\mathrm{InBr}$ are diffuse having intensity fluctuations (Huber \& Herzberg 1979). These bands extend up to $3100 \AA$ at $470^{\circ} \mathrm{C}$. Discrete bands of $A \leftarrow X$ and $B \leftarrow X$ systems of $\mathrm{InBr}$ were also observed at $250^{\circ} \mathrm{C}$. The electronic spectrum of $\mathrm{InBr}$ was investigated because a new broad band emission was observed in our laboratory (Singh et al 1991) at $\sim 5200 \AA$ for $\operatorname{InBr}$ that has the potential to be developed into an efficient excimer laser medium.

\section{Conclusion}

The cylindrical furnace constructed for absorption spectral studies is able to provide a maximum temperature of $1100^{\circ} \mathrm{C}$ and is very useful in the study of absorption spectra of free radicals at different temperatures. The temperature control of the furnace is 
quite precise since the set temperature is maintained nicely with a variation of only $\pm 1^{\circ} \mathrm{C}$. The power rating of the furnace is of the order of $2 \mathrm{KW}$.

The author acknowledges with gratitude the technical help and guidance extended during the course of this work by Dr M Singh, formerly of Spectroscopy Division, BARC. The author expresses his sincere thanks to M/s A B Tamhane, Radio Metallurgy Division, and N T Parekh of the Material Science Division for their valuable suggestions in the construction of the furnace.

\section{References}

Huber K P, Herzberg G 1979 Molecular spectra and molecular structure (New York: Van Nostrand Reinhold) vol. 4

Lord Rayleigh 1927 Series of emission and absorption bands in the mercury spectrum. Proc. $R$. Soc. London A116: 702-719

Mies F H, Stevens W J, Krauss M 1978 Model calculation of the electronic structure and spectroscopy of $\mathrm{Hg}_{2}$. J. Mol. Spectrosc. 72: 303-331

Singh M, Ghodgaonkar G S, Saksena M D 1991 A new emission spectrum of indium bromide at 5200 Å. J. Quant. Spectrosc. Radiat. Transfer 46: 583-586 